\title{
Article
}

\section{C1206, a novel curcumin derivative, potently inhibits Hsp90 and human chronic myeloid leukemia cells in vitro}

\author{
Ying-juan FAN ${ }^{1,2}$, Yi-xiang ZHOU ${ }^{3}$, Lian-ru ZHANG ${ }^{4}$, Qiao-fa LIN¹, ${ }^{1,}$ Ping-zhang GAO ${ }^{5}$, Fang CAI ${ }^{1,2}$, Li-ping ZHU1, 2 , Bi LIU ${ }^{1,2}$, \\ Jian-hua $X U^{1,2, *}$ \\ ${ }^{1}$ School of Pharmacy, Fujian Medical University, Fuzhou 350108, China; ${ }^{2}$ Fuijan Provincial Key Laboratory of Natural Medicine \\ Pharmacology, Fuzhou 350108, China; ${ }^{3}$ Department of Pharmacy, Xiamen Xianyue Hospital, Xiamen 361012, China; ${ }^{4}$ School of Life \\ Science, Xiamen University, Xiamen 361005, China; ${ }^{5}$ College of Chemistry and Life Science, Quanzhou Normal University, Quanzhou \\ 362000, China
}

\begin{abstract}
4-(4-Pyridinyl methylene) curcumin (C1206) is a new derivative of curcumin that is more active than curcumin in inhibition of heat shock protein 90 (Hsp90) and antitumor action. In this study we investigated the relationship between C1206-induced inhibition of Hsp90 and its anti-leukemic effects. The fluorescence quenching experiments showed that C1206 seemed to bind the middle dimerization domain of Hsp90. The interaction between $\mathrm{C} 1206$ and Hsp90 was driven mainly by electrostatic interaction. In in vitro

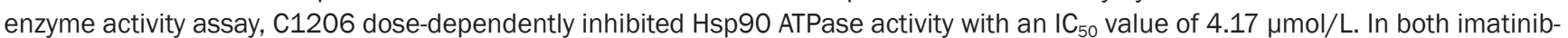

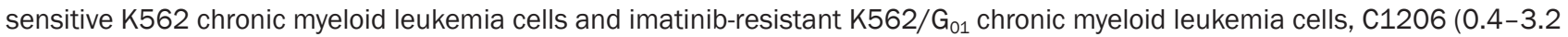
$\mu \mathrm{mol} / \mathrm{L}$ ) dose-dependently caused the degradation of Hsp90 client proteins and downstream proteins (AKT, MEK, ERK, C-RAF, P-AKT,

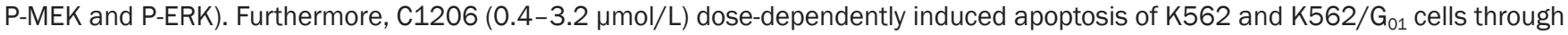
triggering mitochondrial pathway. Consistent with this result, $\mathrm{C} 1206$ inhibited the proliferation of $\mathrm{K} 62$ and $\mathrm{K}_{562} / \mathrm{G}_{01}$ cells with IC $_{50}$ values of 1.10 and $0.60 \mu \mathrm{mol} / \mathrm{L}$, respectively. These results suggest that $\mathrm{C} 1206$ is a novel Hsp90 inhibitor and a promising therapeutic agent for chronic myeloid leukemia.
\end{abstract}

Keywords: curcumin derivative; Hsp90 inhibitor; anticancer drug; ATPase activity; apoptosis; mitochondria; chronic myeloid leukemia; K562 cells; K562/G $\mathrm{G}_{01}$ cells

Acta Pharmacologica Sinica (2018) 39: 649-658; doi: 10.1038/aps.2017.160; published online 7 Dec 2017

\section{Introduction}

Heat shock protein 90 (Hsp90) is a highly conserved molecular chaperone involved in the maturation and stabilization of over 200 oncogenic client proteins ${ }^{[1,2]}$. Most Hsp90 client proteins, such as epidermal growth factor receptor (EGFR), AKT, C-Raf (also called Raf-1), Cdk4, Bcr-Abl, and p53, are essential for tumor growth, proliferation and survival ${ }^{[3-5]}$. Therefore, Hsp90 is a key protein in oncogenesis and malignancy and has recently become an emerging target for cancer therapeutics ${ }^{[6]}$. Hence, Hsp90 inhibitors have significant potential as antitumor compounds. Hsp90 inhibitors can cause chaperone complexes to dissociate and can lead to the degradation of Hsp90 client proteins by stimulating their presentation to proteins involved in the degradation pathway.

\footnotetext{
${ }^{*}$ To whom correspondence should be addressed. E-mail xjh@mail.fjmu.edu.cn

Received 2017-05-01 Accepted 2017-08-16
}

Curcumin is an active ingredient of the plant turmeric (Curcuma longa). In our previous work ${ }^{[7]}$, we found that curcumin is a lead compound of Hsp90 inhibitors. We thus synthesized a series of derivatives, some of which showed lead-like properties and were shown to be more active than curcumin in Hsp90 inhibition and antitumor action ${ }^{[8,9]}$. In this study, we investigate a novel curcumin derivative, 4-(4-pyridinyl methylene) curcumin (C1206), for its interaction with Hsp90 and its anti-leukemia effects. Our results show that C1206 significantly inhibits proliferation and induces apoptosis in K562 and $\mathrm{K} 562 / \mathrm{G}_{01}$, which may be related to the C1206-induced effects on the molecular chaperone functions of Hsp90 and its downregulation of Hsp90 client proteins. These data suggest that C1206 is a potent Hsp90 inhibitor with anti-leukemic effects.

\section{Materials and methods}

Materials and reagents

The bacterial strains and plasmids were obtained from the 
School of Life Science of Xiamen University, China. C1206 was designed and synthesized by our laboratory (Figure 1A). $\mathrm{Ni}^{2+}$-nitrilotriacetic acid (NTA) agarose was purchased from General Electric (Little Chalfont, Buckinghamshire, UK). Geldanamycin (GA) was purchased from Shanghai Sangon Biological Engineering (Lot № XP0806132012J, Shanghai, China). ATP was purchased from Sigma-Aldrich (St Louis, MO, USA). The stock solution of Hsp90, which was expressed and purified by our laboratory, was prepared in a $10 \mathrm{mmol} / \mathrm{L}$ PBS buffer at $\mathrm{pH} 7.4$, and the applied concentration was fixed at $5.0 \mu \mathrm{mol} / \mathrm{L}$. C1206 was dissolved in 5\% DMSO for fluorescence measurements. Anti-Akt, anti-p-Akt, anti-Mek, antiP-Mek, anti-Erk, anti-P-Erk, anti-C-Raf, anti-P-C-Raf, antiHsp90, anti-Hsp70, anti-Hop, anti-P23, anti- $\beta$-Actin, anti-Bax, anti-Bcl-2 (an apoptosis suppression protein) and the Apoptosis Antibody Sampler Kit (\#9915, caspase-3, cleaved caspase-3, caspase-9, cleaved caspase-9, caspase-7, cleaved caspase-7) were purchased from Cell Signaling Technology, Inc (Danvers, MA, USA). The water used in the experiments was thricedistilled using Milli-Q Biocel systern (Millipore, Biocel, MA, USA). All other reagents were of analytical reagent grade.

\section{Cloning, expression, and purification of Hsp90}

The cloning, expression and purification of the various constructs of Hsp90, including the histidine (his)-tagged yeast full-length Hsp90 (1-732, $90 \mathrm{kDa})$, the N-terminal domain of Hsp90 (N-Hsp90, 1-236, $25 \mathrm{kDa}$ ), the middle domain of Hsp90 (M-Hsp90, 272-617, $40 \mathrm{kDa}$ ), and the C-terminal domain of Hsp90 (C-Hsp90, 629-732, $15 \mathrm{kDa}$ ), have been previously described ${ }^{[10]}$.

\section{Fluorescent measurements}

Samples were excited at $280 \mathrm{~nm}$, and fluorescence intensi-
A<smiles>COc1cc(/C=C/C(=O)C(=O)/C=C/c2ccc(O)c(OC)c2)ccn1</smiles>

4-(4-Pyridinyl methylene) curcumin (Molecular weight 458.15)
B

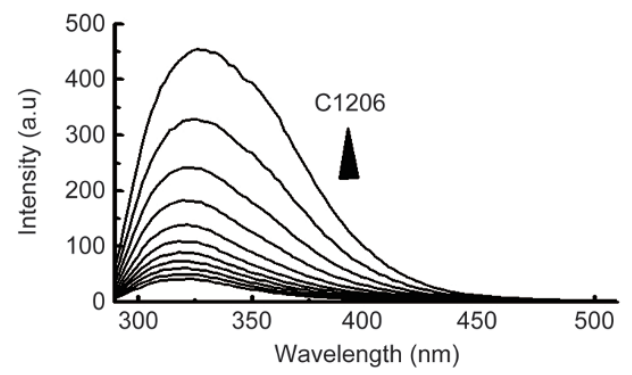

C

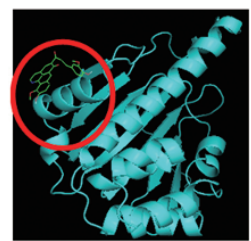

$\mathrm{F}$

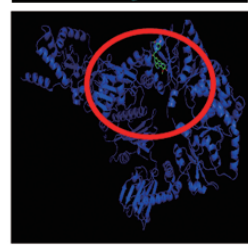

D

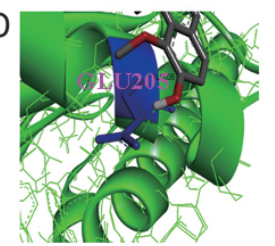

$\mathrm{E}$

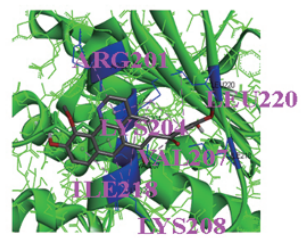

$\mathrm{H}$
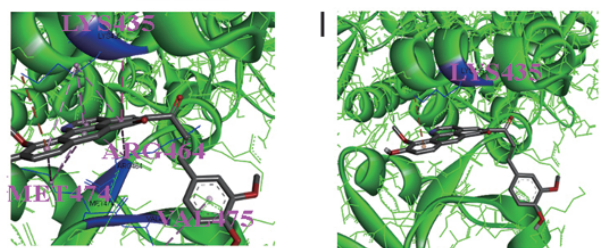

$\mathrm{K}$

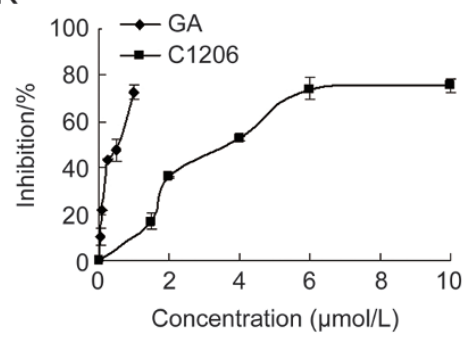

Figure 1. C1206 physically binds to the Hsp90 and inhibits Hsp90 ATPase activity. (A) Chemical structure of C1206. The molecular weight of C1206 is 458.15. (B) Quenching effect of C1206 (0-50 $\mu \mathrm{mol} / \mathrm{L})$ on Hsp90 endogenous fluorescent in a concentration-dependent manner. The vertical and horizontal axes represent the fluorescent intensity and emission wavelength, respectively. The excitation wavelength is $280 \mathrm{~nm}$, whereas the Hsp90 emission peak is at $337 \mathrm{~nm}$. (C-E) C1206 dock to N-terminal Hsp90. (F-I) C1206 dock to C-terminal Hsp90. (J) Synchronous fluorescence spectra of $\mathrm{C} 1206$ (0-50 $\mu \mathrm{mol} / \mathrm{L})$ with Hsp90 (a) $\Delta \lambda=15 \mathrm{~nm}$, (b) $\Delta \lambda=60 \mathrm{~nm}$. The vertical and horizontal axes represent the fluorescent intensity and emission wavelength, respectively. (K) The inhibition rate of Hsp90 ATPase activity under the different concentration of GA and C1206 (0-10 $\mu$ mol/L). The results represent the mean \pm SEM of triplicate experiments. 
ties were recorded in the range of $290-500 \mathrm{~nm}$ at $293 \mathrm{~K}, 303 \mathrm{~K}$ and $310 \mathrm{~K}$ using a Cary Eclipse spectrofluorometer (Varian, Palo Alto, CA, USA). The fluorometric titration experiments were performed in $2.0 \mathrm{~mL}$ of $5.0 \mu \mathrm{mol} / \mathrm{L} \mathrm{Hsp90} \mathrm{solution} \mathrm{(10}$ $\mathrm{mmol} / \mathrm{L}$ PBS buffer, $\mathrm{pH}$ 7.6) with successive additions of C1206 solution (in $0.2 \%$ DMSO) from 5 to $50 \mu \mathrm{mol} / \mathrm{L}$. All tests were performed in triplicate ${ }^{[11]}$.

\section{Hsp90 ATPase activity assay}

The experiments were incubated in $100 \mu \mathrm{L}$ of $0.4 \mu \mathrm{mol} / \mathrm{L}$ Hsp90 and $1 \mathrm{mmol} / \mathrm{L}$ ATP and different concentrations of C1206, GA or vehicle (DMSO) in assay buffer $(6 \mathrm{mmol} / \mathrm{L}$ $\mathrm{MgCl}_{2}, 20 \mathrm{mmol} / \mathrm{L} \mathrm{KCl}$ and $100 \mathrm{mmol} / \mathrm{L}$ Tris-HCl, $\mathrm{pH} \mathrm{7.4)} \mathrm{at}$ $310 \mathrm{~K}$ for $3 \mathrm{~h}$. At the end of the incubation, the ATPase activity of Hsp90 was assessed by malachite green reagent $(w / v$, $0.0812 \%$ malachite green, $2.32 \%$ polyvinyl alcohol, $5.72 \%$ ammonium molybdate in $6 \mathrm{~mol} / \mathrm{L} \mathrm{HCl}$ and argon water mixed in a ratio of $2: 1: 1: 2)$. Cultures were analyzed in triplicate at an absorbance of $620 \mathrm{~nm}^{[10]}$. Kinetic analysis of Hsp90 ATPase activity was carried out using a nonlinear regression fit of the experimental points to the Michaelis-Menten equation. To obtain $K_{\mathrm{m}}$ and $V$ values, the Eadie-Hofstee linear transformation ( $V$ against $V /[s]$ ) was used, with the slope $=-K_{\mathrm{m}}$ and the intercept on the $\mathrm{x}$-axis $=V / K_{\mathrm{m}}{ }^{[10]}$.

\section{Cell culture}

Human K562 leukemia cells were cultured in RPMI-1640 medium containing $10 \%$ heat-inactivated fetal bovine serum, $100 \mathrm{U} / \mathrm{mL}$ penicillin, and $100 \mathrm{mg} / \mathrm{mL}$ streptomycin (medium A) at $37^{\circ} \mathrm{C}$ in a $5 \% \mathrm{CO}_{2}$ atmosphere. $\mathrm{K} 562 / \mathrm{G}_{01}$ cells were maintained in medium A containing $4 \mu \mathrm{mol} / \mathrm{L}$ imatinib.

\section{Cell proliferation assays MTT assays}

Exponentially growing cells were incubated in triplicate in 96-well plates at a final concentration of $5 \times 10^{4}$ cells $/ \mathrm{mL}$ in the presence or absence of $\mathrm{C} 1206$ for $24 \mathrm{~h}$ at $37^{\circ} \mathrm{C}$. Cell proliferation was measured using the 3-(4,5-dimethylthiazol-2-yl)2,5-diphenyltetrazolium bromide (MTT; Sigma Chemical Company, St Louis, MO, USA) colorimetric dye reduction method. The inhibitory effect of C1206 on cell growth was expressed as an $\mathrm{IC}_{50}$ value.

\section{CFSE staining assays}

Exponentially growing cells were resuspended in the CFSE staining solution at $37^{\circ} \mathrm{C}$ for $10 \mathrm{~min}$. After washing with cold RPMI-1640 medium containing 10\% heat-inactivated fetal bovine serum, cells were grown in 12-well plates at a final concentration of $3 \times 10^{5}$ cells $/ \mathrm{mL}$ in the presence or absence of $\mathrm{C} 1206$ for $72 \mathrm{~h}$ at $37^{\circ} \mathrm{C}$. The cells were resuspended in PBS and then analyzed by flow cytometry.

\section{Apoptosis assessment by annexin-V staining}

Following the drug treatments, the cells were resuspended in $100 \mu \mathrm{L}$ of staining solution containing annexin-V-FITC/PI in
HEPES buffer (10 mmol/L HEPES, pH 7.4, 150 mmol/L NaCl, $5 \mathrm{mmol} / \mathrm{L} \mathrm{KCl}, 1 \mathrm{mmol} / \mathrm{L} \mathrm{MgCl}_{2}$, and $2 \mathrm{mmol} / \mathrm{L} \mathrm{CaCl}_{2}$ ). These reagents were supplied with the Annexin-V-FITC/PI Double Staining Kit (F Hoffmann-La Roche, Ltd, Basel, BaselStadt, Switzerland) and were used according to the manufacturer's instructions. After incubation at RT for $15 \mathrm{~min}$ in the dark, the cells were analyzed using a flow cytometer (BD FACSCanto II, BD Biosciences, Franklin, NJ, USA). Annexin-V bound to cells that expressed phosphatidylserine on the outer layer of the cell membrane. Cells that stained positive for Annexin-V were scored as apoptotic cells ${ }^{[12]}$.

\section{JC-1 mitochondrial membrane potential (MMP) assay}

Following the drug treatments, the cells were resuspended in the staining solution provided with the JC-1 Mitochondrial Membrane Potential Assay Kit (KeyGEN Biotech, Nanjing, China) according to the manufacturer's instructions. After incubation at RT for $10 \mathrm{~min}$ in the dark, the cells were analyzed using a flow cytometer.

\section{Cell cycle assessment by PI staining}

Following the drug treatments, the cells were resuspended in PBS and fixed with $70 \%$ ethanol overnight at $-20^{\circ} \mathrm{C}$. After washing with cold PBS, cells were incubated with DNase-free RNase and propidium iodide (PI) at $37^{\circ} \mathrm{C}$ for $30 \mathrm{~min}$. Cells were then analyzed by flow cytometry.

\section{Western blot analysis}

Total protein extracts were resolved by sodium dodecyl sulfate polyacrylamide gel electrophoresis (SDS-PAGE). After electrophoresis, the proteins were transferred to a PVDF membrane $\left(150 \mathrm{~mA}, 4^{\circ} \mathrm{C}\right)$ for $1.5 \mathrm{~h}$. The membranes were blocked in blocking buffer (1\% BSA, Tris-HCl $20 \mathrm{mmol} / \mathrm{L}, \mathrm{pH}$ 7.5, $\mathrm{NaCl} 150 \mathrm{mmol} / \mathrm{L}$, and $0.05 \%$ Tween-20) for $1 \mathrm{~h}$ at RT, followed by incubation with the relevant antibody overnight at $4{ }^{\circ} \mathrm{C}$. The membranes were then incubated with anti-rabbit peroxidase-conjugated secondary IgG antibodies and developed with an enhanced chemiluminescence (ECL) substrate. The membranes were scanned on a Carestream Image Station System to visualize the bands.

\section{Down-regulation of Hsp90 with siRNA}

$\mathrm{K} 562$ and $\mathrm{K} 562 / \mathrm{G}_{01}$ cells were seeded in antibiotic-free normal growth medium supplemented with fetal bovine serum. Single-strand siRNA oligonucleotides targeting human Hsp90a/ $\beta$ (sc-35608, Santa Cruz Biotechnology, Dallas, TX, USA) and control siRNA (sc-37007) were diluted in siRNA transfection medium (sc-36868) and mixed with siRNA transfection reagent (sc-29528) according to the manufacturer's protocol. $\mathrm{K} 562$ and $\mathrm{K} 562 / \mathrm{G}_{01}$ cells were incubated with the transfection complexes for $6 \mathrm{~h}$ and in the normal growth medium for $24 \mathrm{~h}$. The cells were allowed to grow for an additional 96 $\mathrm{h}$ to test cell proliferation, and the cell number of the siRNAtreated group was compared with that of the control group to calculate the inhibition rate. The knockdown of Hsp90 was confirmed by Western blotting. 


\section{Statistical analysis}

All data were analyzed with two-sided unpaired $t$-tests using the GraphPad software package for Windows (Prism version 5.0) and Origin 8.5 software. Values are expressed as the mean values of triplicate or duplicate experiments.

\section{Results}

\section{C1206 interacts physically with Hsp90}

The binding of C1206 to Hsp90 was characterized by fluorescence quenching experiments. At an excitation wavelength $280 \mathrm{~nm}$, the interaction was examined with a fluorescence spectrum from $290 \mathrm{~nm}$ to $510 \mathrm{~nm}$. His-tagged Hsp90 displayed maximal fluorescence at $337 \mathrm{~nm}$. When Hsp90 was incubated with increasing concentrations of C1206, the fluorescence intensity gradually decreased with a slight blueshift of

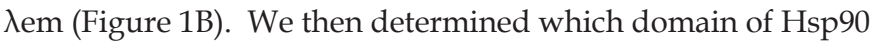
is involved in binding C1206 by constructing three truncation segments of Hsp90: the N-terminal domain (N-Hsp90), the middle domain (M-Hsp90) and the C-terminal domain (C-Hsp90), corresponding to its ATP-binding domain, its cochaperone binding domain and its dimerization domain, respectively. The fluorescence intensity of M-Hsp90, but not N-Hsp90 or C-Hsp90, was most obviously quenched with increasing concentrations of C1206, indicating that C1206 interacts with the middle domain.

Using the equation previously described ${ }^{[10]}$, the titration curves for Hsp90 and M-Hsp90 yielded estimated dissociation constants $\left(K_{\mathrm{D}}\right)$ of $\mathrm{C} 1206$ of $15.226 \pm 0.714 \mu \mathrm{mol} / \mathrm{L}$ and $5.838 \pm 1.070 \mu \mathrm{mol} / \mathrm{L}$, respectively, indicating that there was a binding interaction between them and that C1206 quenched the intrinsic fluorescence of Hsp90 ${ }^{[13]}$.

The quenching process can be analyzed by Stern-Volmer equation, which has been previously described ${ }^{[14]}$. Values of the quenching constant $\left(K_{\mathrm{sv})}\right.$ and the quenching rate constant $\left(K_{\mathrm{q}}\right)$ were obtained from their respective slopes. For all types of quenching agents acting on biological macromolecules, the maximum diffusion-controlled dynamic collision quenching rate has a constant value of $2.0 \times 10^{10} \mathrm{~L} \cdot \mathrm{mol}^{-1} \cdot \mathrm{s}^{-1}$. The quenching rate constant $K_{\mathrm{q}}$ value of $\mathrm{C} 1206\left((25.383 \pm 2.078) \times 10^{12} \mathrm{~L} \cdot \mathrm{mol}^{-1} \cdot \mathrm{s}^{-1}\right)$ was greater than $2.0 \times 10^{10} \mathrm{~L} \cdot \mathrm{mol}^{-1} \cdot \mathrm{s}^{-1}$, which indicated that the quenching effect of $\mathrm{C} 1206$ on Hsp90 intrinsic fluorescence was not due to molecules colliding by dynamic quenching but to the formation of the complex by static quenching ${ }^{[15]}$.

Static quenching complies with the Lineweaver-Burk equation, which has been previously described ${ }^{[16]}$. Values of the apparent binding constant $\left(K_{\mathrm{A}}\right)$ of $\mathrm{C} 1206\left(2.523 \times 10^{7} \mathrm{~L} / \mathrm{mol}\right)$ and the binding site (n) of C1206 (1.475 \pm 0.041$)$ were obtained from their intercept and slope, respectively.

The thermodynamic enthalpy change $\left(\Delta H^{\theta}\right)$, entropy change $\left(\Delta S^{\theta}\right)$ and free energy change $\left(\Delta G^{\theta}\right)$ of C1206-Hsp90 binding were also calculated from the fluorescent spectrum, yielding $-5.50 \pm 2.08 \mathrm{~kJ} / \mathrm{mol}, 74.5 \pm 6.86 \mathrm{~J} \cdot \mathrm{mol}^{-1} \cdot \mathrm{k}^{-1}$ and $-28.00 \pm 0.13 \mathrm{~kJ} / \mathrm{mol}$, respectively. The negative enthalpy change and positive entropy change suggest that electrostatic interactions predominate in stabilizing the C1206-Hsp90 complex ${ }^{[17]}$.

We investigated the predicted binding of C1206 to N-Hsp90 and C-Hsp90 with structural modeling. In the model of the binding of C1206 with the N-terminus of Hsp90 (Figure 1C), hydrogen bonds were formed between C1206 and residue GLU205 in N-Hsp90 (Figure 1D). Hydrophobic packing interactions were formed between C1206 and residues LEU220, LYS204, VAL207, LYS208, ILE218 and ARG201 of N-Hsp90 (Figure 1E). In comparison, in the model of the binding of C1206 with the C-terminus of Hsp90 (Figure 1F), hydrogen bonds were formed between C1206 and residues GLU439, TYR466 and ASP479 in C-Hsp90 (Figure 1G). Hydrophobic packing interactions were predicted between C1206 and residues LYS435, ARG464, MET474 and VAL475 in C-Hsp90 (Figure $1 \mathrm{H})$. Specifically, van der Waals contacts formed between C1206 and residue LYS435 in C-Hsp90 (Figure 1I).

Tyrosine and tryptophan are the main sources of protein fluorescence. When the D-value $(\Delta \lambda)$ between excitation and emission wavelengths was stabilized at 15 or $60 \mathrm{~nm}$, the characteristic patterns in the synchronous fluorescence spectra can provide information on the Tyr or Trp residues ${ }^{[18]}$. When $\Delta \lambda$ was $15 \mathrm{~nm}$, increasing concentrations of C1206 did not cause the fluorescence peak position of Tyr residues to shift (Figure 1J), which meant that the microenvironment of Tyr residues did not change after binding and that microenvironment hydrophobicity did not obviously decrease. The conformation of the Tyr residue of Hsp90 did not change. As shown in Figure 1J, the addition of C1206 led to a dramatic decrease in fluorescence intensity with a slight blueshift of $\lambda_{\mathrm{em}}$. The blueshift indicated that the polarity around the tryptophan residues decreased and that hydrophobicity increased.

\section{C1206 inhibits the ATPase activity of Hsp90}

To characterize the inhibition of Hsp90 by C1206 binding, a colorimetric assay for inorganic phosphate based on the formation of a phosphomolybdate complex and subsequent reaction with malachite green were used to measure the inhibitory effects of C1206 on the ATPase activity of Hsp90 ${ }^{[10]}$. When the concentration of ATP was $1 \mathrm{mmol} / \mathrm{L}$, the inhibition of Hsp90 ATPase activity of C1206 with the $\mathrm{IC}_{50}$ values was 4.17 $\mathrm{mmol} / \mathrm{L}$. C1206 inhibits Hsp90 ATPase activity potently (Figure $1 \mathrm{~K})$.

\section{C1206 damages the molecular chaperone functions of Hsp90 and down-regulates Hsp90 client proteins in $\mathrm{K} 562$ and $\mathrm{K} 562 / \mathrm{G}_{01}$ cells}

C1206 inhibited the molecular chaperone functions of Hsp90 and induced the degradation of Hsp90 client proteins, as shown by Western blotting. The results presented in Figure 2A and 2B indicate that C1206 altered the composition of molecular chaperone complexes associated with Hsp90 (Figure 2A) and that increasing concentrations of C1206 reduced the levels of Hsp90 client proteins, such as AKT, Raf, MEK, and ERK, in both imatinib-sensitive K562 cells and imatinibresistant $\mathrm{K} 562 / \mathrm{G}_{01}$ cells. Their phosphorylated forms also decreased in a similar manner with increasing doses of C1206 (Figure 2B). Interestingly, the inhibition efficiency of C1206 is of the same order of magnitude as that of GA, as measured by 
A

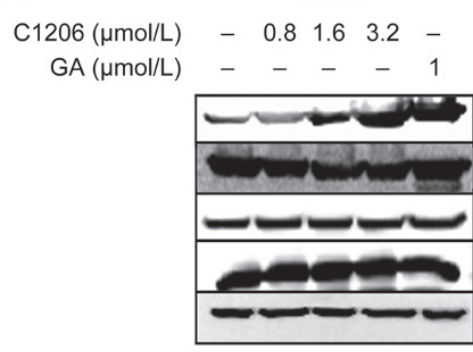

B

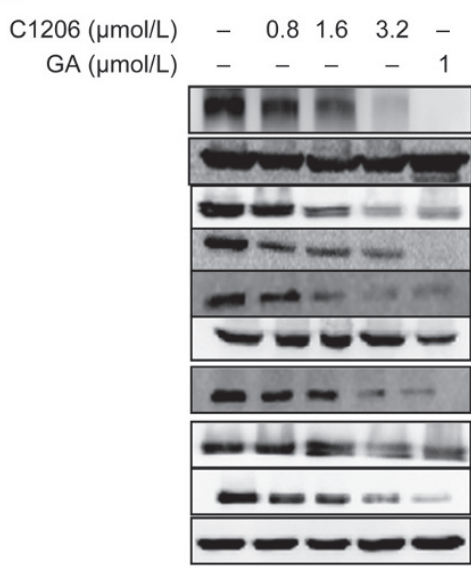

K562/G 01
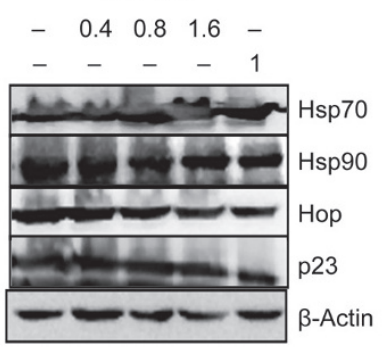

$\mathrm{K} 562 / \mathrm{G}_{01}$

- 0.40 .81 .6 -

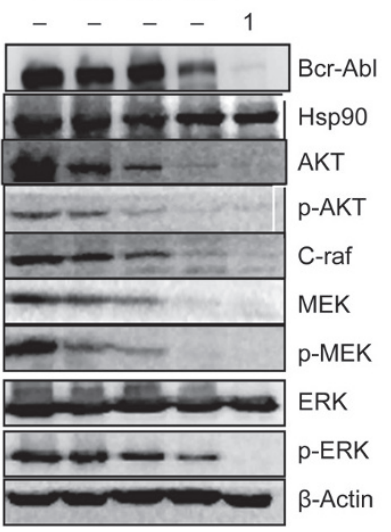

C

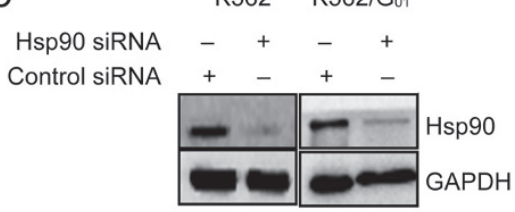

D

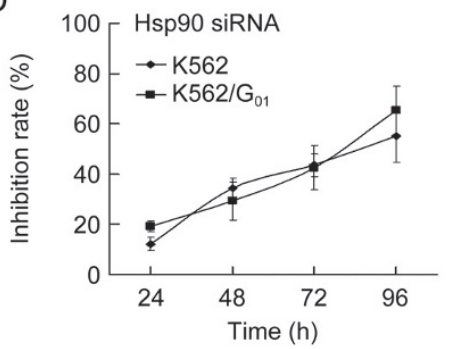

Figure 2. C1206 affected the molecular chaperone functions of Hsp90 and down-regulated client proteins level of Hsp90 in imatinib-sensitive or imatinib-resistant CML cells. $\mathrm{K} 562$ and $\mathrm{K} 562 / \mathrm{G}_{01}$ cells were treated with indicated concentrations of $\mathrm{C} 1206$ for $24 \mathrm{~h}$. The expression levels of (A) molecular chaperone of $\mathrm{Hsp90}$ and (B) client proteins of Hsp90 were monitored by Western blot analysis. RNA interference in CML cells. (C) siRNA reduced the expression of $\mathrm{Hsp90}$ in $\mathrm{K} 562$ and $\mathrm{K} 562 / \mathrm{G}_{01}$. (D) Effects of siRNA on cell proliferation. Viable cells were counted by typan blue exclusion assays. The inhibition rate was calculated by comparing the cell number of the siRNA-treated group with that of the control group. The results represent the mean \pm SEM of triplicate experiments.

the degradation of a majority of client proteins.

C1206 induces apoptosis in $\mathrm{K} 562$ and $\mathrm{K} 562 / \mathrm{G}_{01}$ cells by triggering the mitochondrial pathway

To determine whether the growth inhibition of imatinibsensitive and imatinib-resistant leukemic cells by C1206 is associated with the induction of apoptosis, we used annexinV-FITC/PI staining and quantified the number of C1206induced apoptotic $\mathrm{K} 562$ and $\mathrm{K} 562 / \mathrm{G}_{01}$ cells. Consistent with the cellular proliferation assay results, apoptosis was induced in a concentration-dependent manner in both the imatinibsensitive K562 cells and imatinib-resistant $\mathrm{K} 562 / \mathrm{G}_{01}$ cells (Figure 3).

The mitochondrial pathway of apoptosis functions in response to various types of stress. A variety of chemotherapeutic agents trigger apoptosis in susceptible cells by inducing MMP disruption, followed by the release of cytochrome $c$, which interacts with cytosolic docking proteins ${ }^{[19-21]}$, thereby facilitating the activation of procaspase- 9 and the subsequent proteolytic processing of procaspase- 3 and procaspase-7. Once activated, these caspases cleave and activate downstream effector caspases, including caspases 3,6 and 7, which in turn cleave nuclear proteins, such as PARP, and induce apoptosis.
MMP is an important parameter of mitochondrial function, which is used as an indicator of cell health. JC-1 selectively enters mitochondria and reversibly changes color from green to red as the MMP increases in healthy cells. By contrast, in apoptotic or unhealthy cells with a low MMP, JC-1 remains in the monomeric form, which only fluoresces green. The ratio of red to green represents the number of healthy cells ${ }^{[22]}$.

These experiments demonstrated that treatment with C1206 led to a significant reduction in MMP, as demonstrated by an increase in the green color of JC-1 and a decrease in the red color of JC-1 (Figure 4A). Therefore, the red/green ratio significantly decreased after C1206 treatment (Figure 4B). A decrease in the MMP promotes the release of cytochrome $c$, which in turn cleaves procaspases 9,7 , and 3 to produce the activate caspases 9,7, and 3 (Figure 4C). These active caspases then cleave PARP and induce apoptosis.

C1206 inhibits proliferation and induces cell cycle arrest in both imatinib-sensitive $\mathrm{K} 562$ and imatinib-resistant $\mathrm{K} 562 / \mathrm{G}_{01}$ cells

To evaluate its effect on cell proliferation, C1206 was administered to $\mathrm{K} 562$ or $\mathrm{K} 562 / \mathrm{G}_{01}$ cells for $24 \mathrm{~h}$, after which the cells were subjected to an MTT assay. A significant inhibition of cell proliferation was observed in a concentration-dependent 

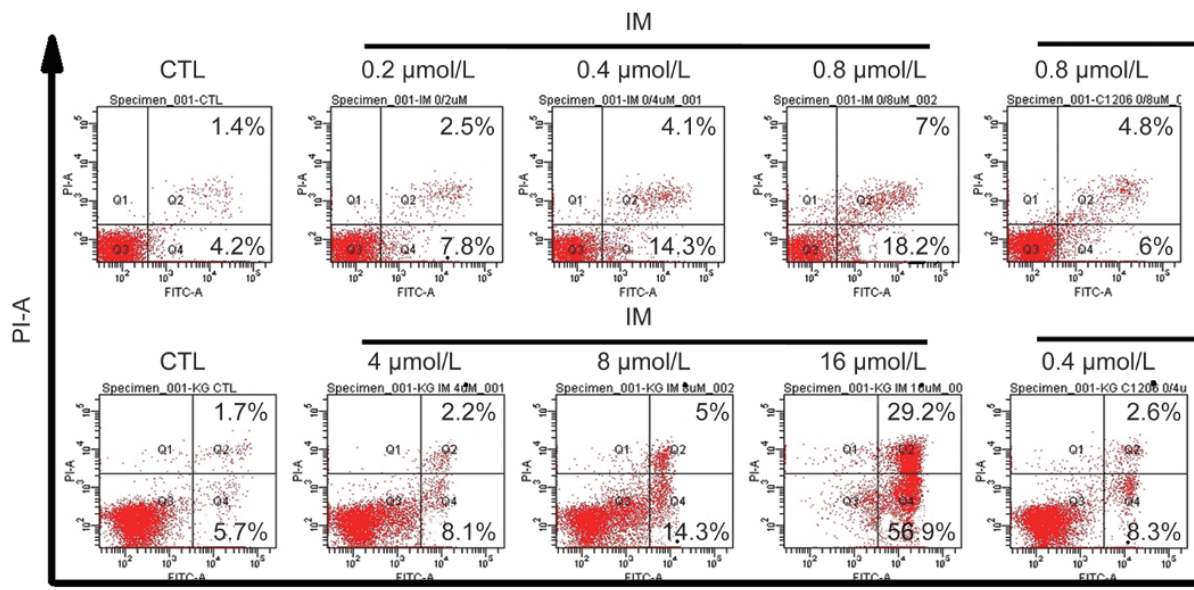

C1206
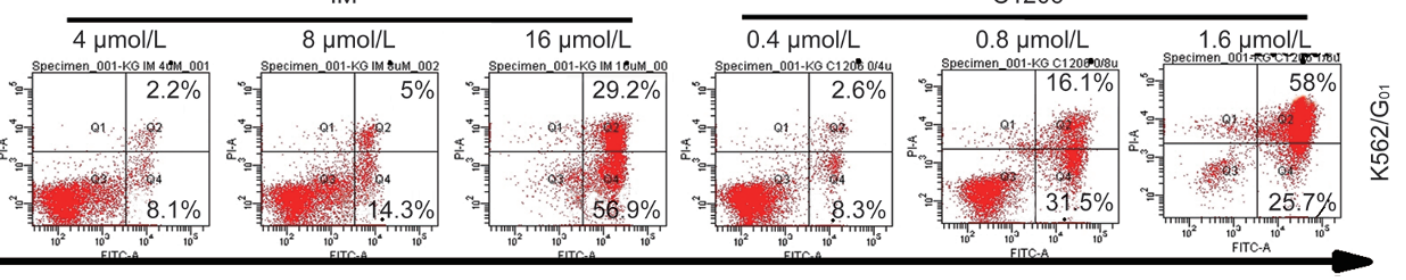

FITC-A
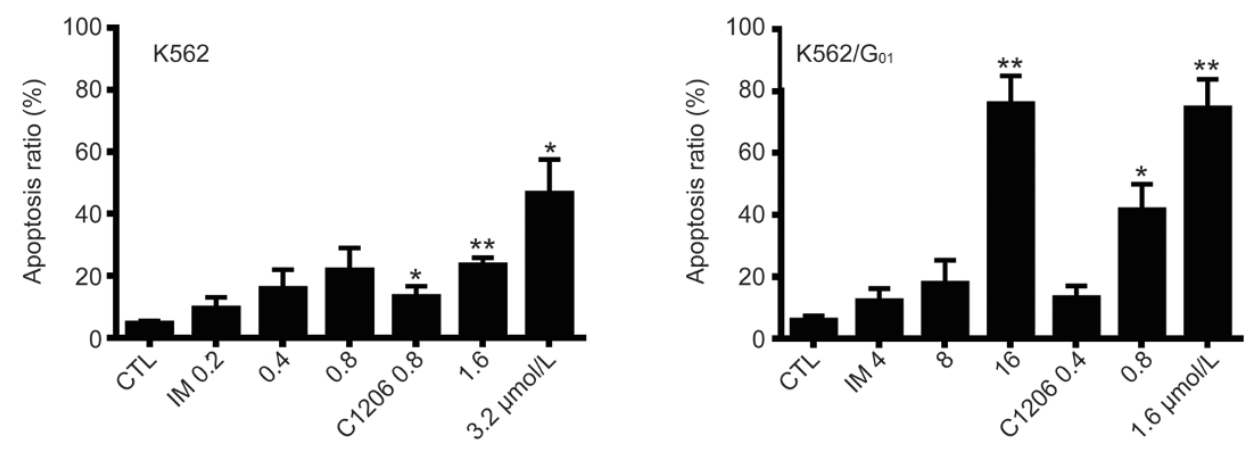

Figure 3. Effect of $\mathrm{C} 1206$ on the induction of apoptosis in imatinib-sensitive or imatinib-resistant CML cells. $\mathrm{K} 562$ and $\mathrm{K} 562 / \mathrm{G}_{01}$ cells were cultured in the presence of $\mathrm{C} 1206$ at the indicated concentrations for $24 \mathrm{~h}$, harvested, double stained with annexin $\mathrm{V}$ and PI and subsequently analysed by flow cytometry. The results represent the mean \pm SEM of triplicate experiments. $\left(n=3,{ }^{*} P<0.05,{ }^{* *} P<0.01\right)$.

manner (Figure 5A). The $\mathrm{IC}_{50}$ values of $\mathrm{C} 1206$ for the $\mathrm{K} 562$ and $\mathrm{K} 562 / \mathrm{G}_{01}$ cell lines were $1.10 \mu \mathrm{mol} / \mathrm{L}$ and $0.60 \mu \mathrm{mol} / \mathrm{L}$, respectively. The dose-dependent inhibition of $\mathrm{K} 562$ or $\mathrm{K} 562 / \mathrm{G}_{01}$ cell proliferation by $\mathrm{C} 1206$ was also shown by CFSE staining assay (Figure 5B and $5 \mathrm{C}$ ). These results indicated that imatinib-resistant $\mathrm{K} 562 / \mathrm{G}_{01}$ cells were also sensitive to $\mathrm{C} 1206$.

To gain further insight into the effects of C1206 on cell proliferation, we next studied the effects of $\mathrm{C} 1206$ on cell cycle distribution. When compared to vehicle controls, C1206-treated cells displayed marked S phase arrest after $24 \mathrm{~h}$ of treatment. The increase in the S phase cell population induced by $\mathrm{C} 1206$ was accompanied by a concomitant decrease in cells in the $\mathrm{G}_{1}$ and $\mathrm{G}_{2} / \mathrm{M}$ phases. These results indicated that $\mathrm{C} 1206$-treated cells were more efficient at inducing $S$ arrest both in $\mathrm{K} 562$ and $\mathrm{K} 562 / \mathrm{G}_{01}$ cells (Figure 6).

\section{Down-regulation of Hsp90 with siRNA confirms the essential role of $\mathrm{Hsp} 90$ targets in CML cell survival}

To further validate the essential role of Hsp90 in CML cell survival, we transfected siRNAs targeting Hsp90 into K562 or $\mathrm{K} 562 / \mathrm{G}_{01}$ cells. The expression of transgenes was confirmed by Western blotting (Figure 2C). Down-regulation of Hsp90 expression significantly inhibited the growth of CML cells (Figure 2D). These results along with data from the C1206 experiments confirmed the essential role of Hsp90 in the anti- leukemia effects of C1206.

\section{Discussion}

Hsp90 is required for the proper folding and maturation of most oncogenic proteins, which can then aberrantly activate multiple signaling pathways ${ }^{[23-25]}$. Therefore, the molecular chaperone Hsp90 is an attractive target for cancer therapy. Most Hsp90 inhibitors have been developed to inhibit Hsp90 chaperone function by binding to Hsp90 $0^{[26]}$. Benzoquinone ansamycin antibiotics, such as geldanamycin (GA) and its derivative 17-allylamino-geldanamycin (17AAG), were the first identified Hsp90 inhibitors ${ }^{[27]}$. Although GA and its derivatives have exhibited potent anticancer effects, severe hepatotoxicity has prevented their clinical development ${ }^{[28]}$. Curcumin showed protective effects against liver injury, could obviously improve the hepatic function and protect the liver ${ }^{[2,30]}$. Further investigation is required to determine whether $\mathrm{C} 1206$ can protect the liver as its parent compound does.

In our previous work ${ }^{[7,31]}$, we found that curcumin inhibited the proliferation of $\mathrm{K} 562$ and $\mathrm{K} 562 / \mathrm{G}_{01}$ cells especially and specifically targeted P210 ${ }^{\mathrm{bcr} / \mathrm{abl}}$, which initiates several signal pathways that are responsible for the resistance of CML cells to several chemotherapeutic agents. Curcumin inhibited the proliferation of $\mathrm{K} 562$ and $\mathrm{K} 562 / \mathrm{G}_{01}$ cells and the inhibitory 
A
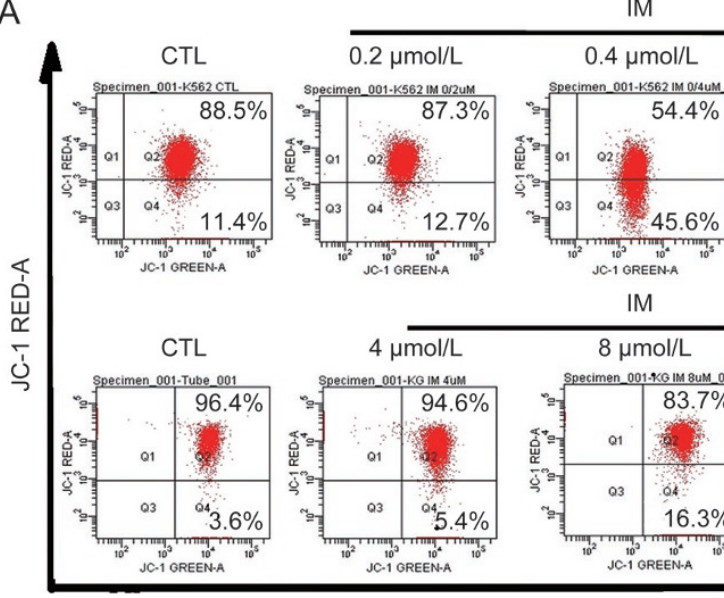

IM

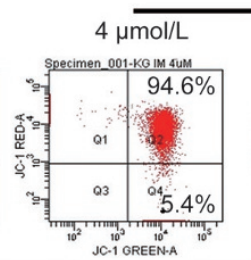

\section{IM}

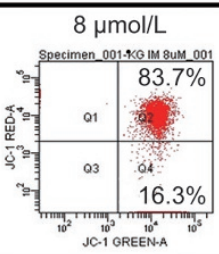

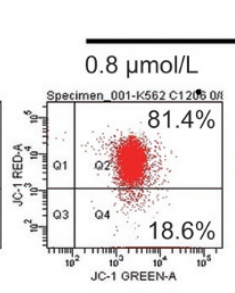

C1206

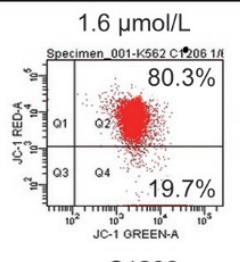

C1206
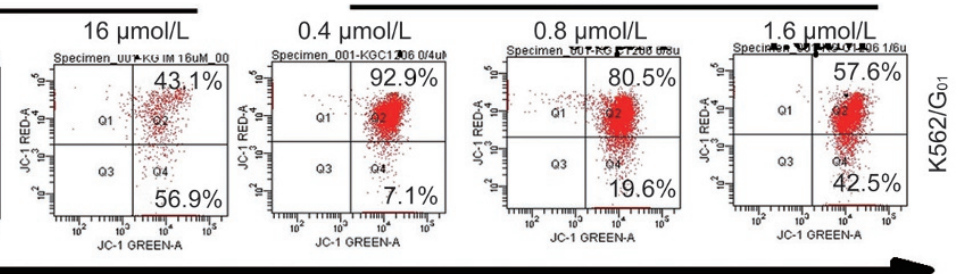

JC-1 GREEN-A

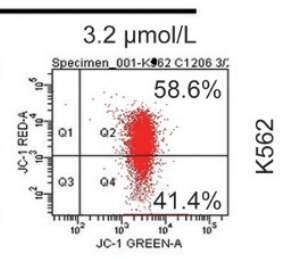

B
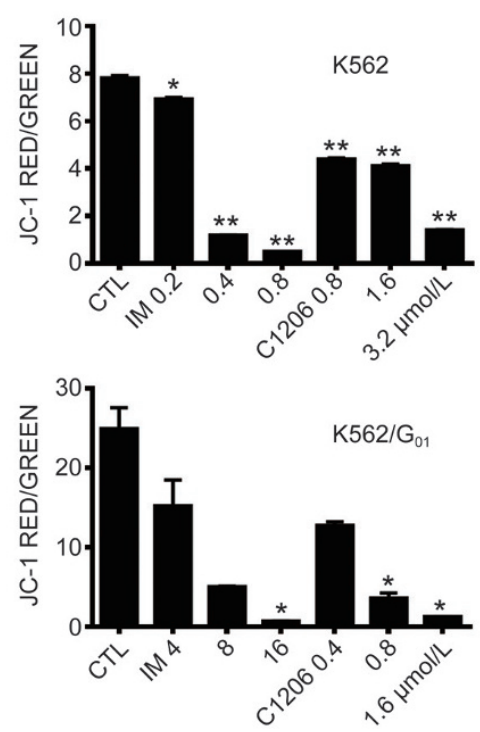

C

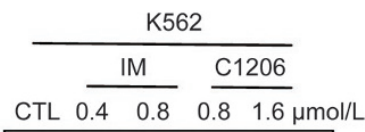

\begin{tabular}{|lllll} 
CTL & 0.4 & 0.8 & 0.8 & 1.6
\end{tabular}

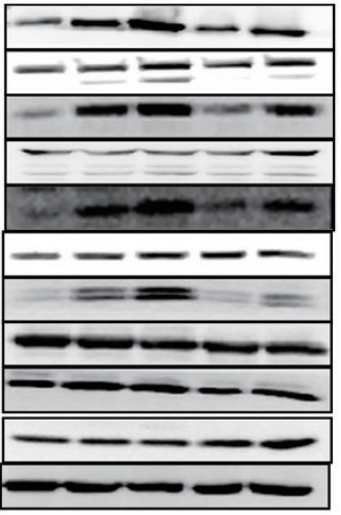

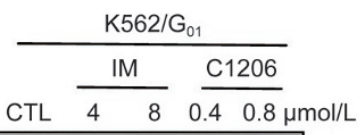

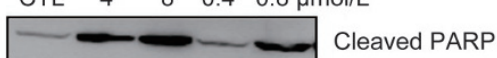
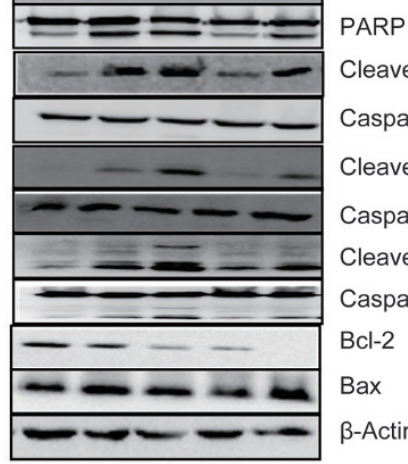

PARP

Cleaved caspase 9

Caspase 9

Cleaved caspase 7

Caspase 7

Cleaved caspase 3

Caspase 3

Bcl-2

Bax

$\beta$-Actin

Figure 4. C1206 triggers the mitochondrial pathway of apoptosis in imatinib-sensitive or imatinib-resistant CML cells. (A) Treatment of K562 or $\mathrm{K} 562 / \mathrm{G}_{01}$ cells with $\mathrm{C} 1206$ at the indicated concentrations for $24 \mathrm{~h}$ significantly reduced the MMP as demonstrated by JC- 1 staining. (B) Quantification of the JC-1 red/green ratio. The results represent the mean \pm SEM of triplicate experiments. $\left(n=3,{ }^{*} P<0.05,{ }^{* * *} P<0.01\right)$. (C) Treatment of imatinibsensitive or imatinib-resistant K562 cells with $\mathrm{C} 1206$ for $24 \mathrm{~h}$ activated caspases 9,7 , and 3 and the PARP pathway as determined by Western blot. $\beta$-Actin served as the protein loading control.

effect was correlated with down-regulation of P210 bcr/abl by curcumin involves disrupting the molecular chaperone functions of Hsp90. Although the parent compound curcumin is a multitargeted anticancer agent, interfering with the effects of tumor necrosis factor, HER2, EGFR, and Bcr-abl, the poor bioavailability of curcumin has limited its clinical application $^{[32,33]}$. To improve the solubility and activity of curcumin, we designed and synthesized C1206. However, further investigation is required to determine whether C1206 inhibits multiple signaling pathways as its parent compound does.

Compared with the known Hsp90 inhibitors, this study showed that C1206 is a novel scaffold unrelated to that of any Hsp90 inhibitor published to date. In the present study, we have shown a strong interaction between C1206 and fulllength Hsp90, N-Hsp90, M-Hsp90 and C-Hsp90. From the binding energy and dissociation constants, we deduce that C1206 is an inhibitor of Hsp90 and is able to bind to the middle domain co-chaperone binding domain of Hsp90. The quenching effect of C1206 on Hsp90 intrinsic fluorescence shows static quenching ${ }^{[34]}$. The thermodynamic parameters and the pattern of synchronous fluorescence suggest that electrostatic interactions predominate in stabilizing the C1206Hsp90 complex. C1206 inhibits the ATPase activity of Hsp90, the binding of C1206 inhibits the catalysis of ATP hydrolysis.

The wide-ranging functions of Hsp90 require a series of cochaperones to drive the chaperone cycle to completion ${ }^{[26]}$. We have shown that C1206 is an Hsp90 inhibitor that directly binds to the middle domain of Hsp90 and inhibits the ATPase activity of Hsp90. This leads to the degradation of multiple Hsp90 client proteins, which may be the primary mechanism 

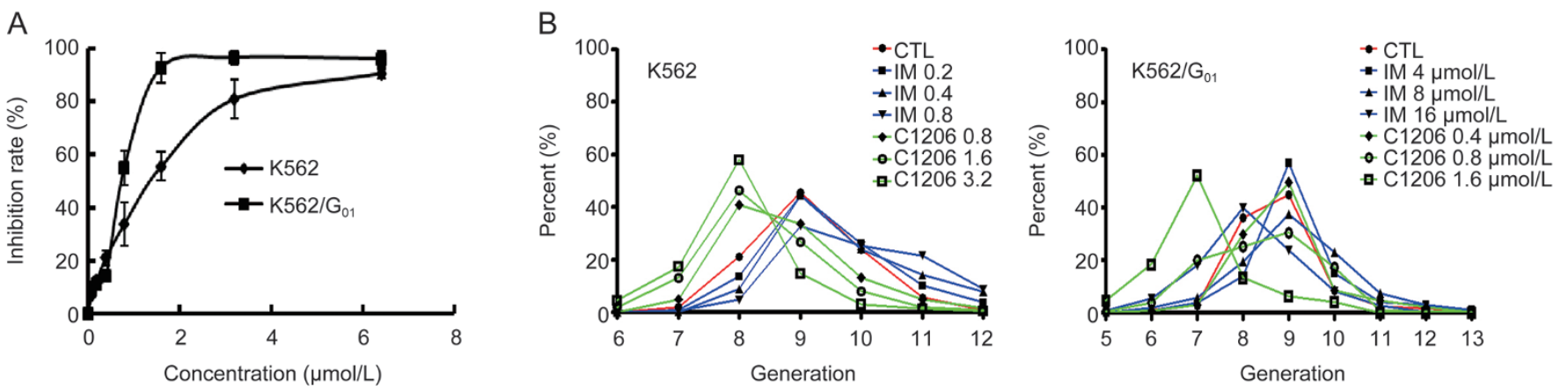

C

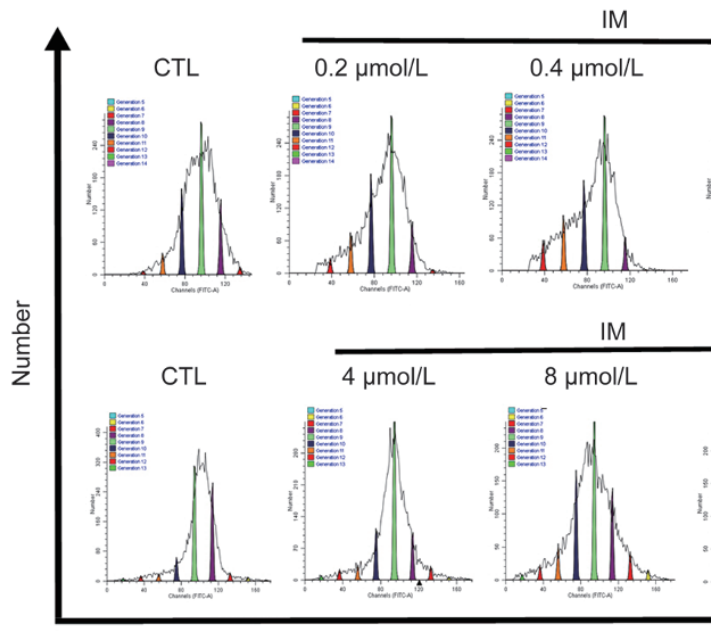

$0.8 \mu \mathrm{mol} / \mathrm{L}$

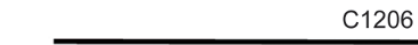

C1206

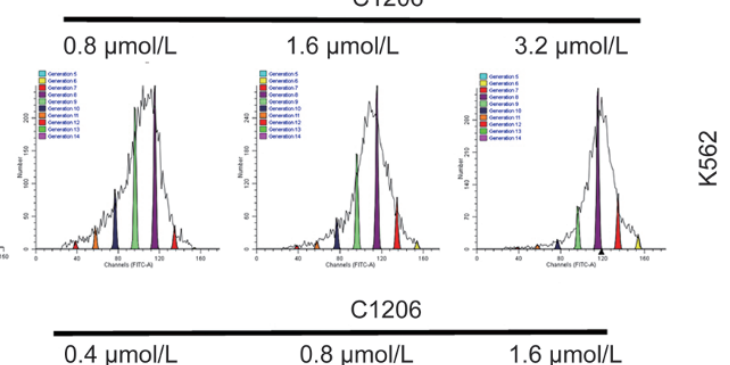

$16 \mu \mathrm{mol} / \mathrm{L}$
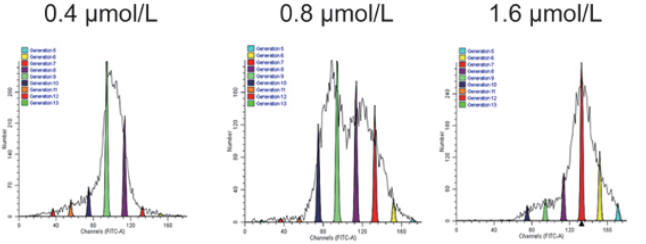

Channels (FITC-A)

Figure 5. $\mathrm{C} 1206$ inhibits the proliferation of $\mathrm{K} 562$ and $\mathrm{K} 562 / \mathrm{G}_{01}$ cells. (A) $\mathrm{K} 562$ and $\mathrm{K} 562 / \mathrm{G}_{01}$ cell lines ware treated with increasing concentrations of $\mathrm{C} 1206(0-6.4 \mu \mathrm{mol} / \mathrm{L})$ for $24 \mathrm{~h}$ and subjected to MTT assay. The results represent the mean \pm SEM of triplicate experiments. The error bars represent the SEM. (B, C) K562 and $\mathrm{K} 562 / \mathrm{G}_{01}$ cells were stained with CFSE and then were treated with $\mathrm{C} 1206$ at the indicated concentrations for $72 \mathrm{~h}$, harvested and subsequently analysed by flow cytometry.

mediating the anticancer effects of C1206. Hsp90 and cochaperone proteins interact with client proteins in an ordered pathway that involves sequential ATP-dependent interactions of the client proteins. The patterns of interacting co-chaperones is likely client protein specific ${ }^{[35,36]}$.

Hsp90 affects the activity of client proteins critical for multiple steps of tumor progression, and it is an important target of cancer therapeutics ${ }^{[37,38]}$. Hsp90 client proteins have varying sensitivity to Hsp90 inhibitors. Hsp90 inhibitors are able to induce degradation of multiple Hsp90 client proteins. For example, proteins levels of the Hsp90 client protein Akt are known to be decreased by Hsp90 inhibition ${ }^{[39]}$. The antagonistic efficacy of C1206 against chronic myeloid leukemia (CML) lines has been investigated at both the molecular and cellular levels. It has been demonstrated that C1206 inhibits CML cell lines $\mathrm{K} 562$ and $\mathrm{K} 562 / \mathrm{G}_{01}$ in a dose-dependent manner. Compared with curcumin, which has $\mathrm{IC}_{50}$ values of $11.67 \mu \mathrm{mol} / \mathrm{L}$ and $6.50 \mu \mathrm{mol} / \mathrm{L}$ for $\mathrm{K} 562$ and $\mathrm{K} 562 / \mathrm{G}_{01}$ cell lines, respectively, C1206 has the advantage. C1206 only slightly inhibited the proliferation of human peripheral blood mononuclear cells (PBMCs). The inhibition rate of PBMCs treated with 100 $\mu \mathrm{mol} / \mathrm{L}$ C1206 for $24 \mathrm{~h}$ was only $47.32 \%$. K562 and K562/G cells treated with different concentrations of C1206 clearly showed that the levels of Akt, P-Akt, Raf, Mek, P-Mek, Erk and P-Erk (Figure 2B) decreased in response to C1206. C1206 was shown to inhibit the proliferation of $\mathrm{K} 562$ and $\mathrm{K} 562 / \mathrm{G}_{01}$ cells through the down-regulation of AKT and Raf/MEK/ERK signal transduction pathway ${ }^{[31]}$. Hsp90 is able to inhibit apoptosis, which aids in tumor cell maintenance. Hsp90 inhibitors targeted to the mitochondria can selectively kill tumor cells ${ }^{[40]}$. C1206 triggers activation of the mitochondrial pathway of apoptosis in $\mathrm{K} 562$ and $\mathrm{K} 562 / \mathrm{G}_{01}$ cells (Figure 4). Moreover, it was shown that $\mathrm{C} 1206$ arrests cell cycle progression.

In conclusion, as a novel Hsp90 inhibitor, $\mathrm{C} 1206$ binds to the middle domain of Hsp90 and inhibits Hsp90 ATPase activity, resulting in the degradation of Hsp90 client proteins. C1206 displays promising antitumor activity against cancer cells in vitro. Our observations provide a basis for the further development of Hsp90-targeted therapy for patients with CML.

\section{Acknowledgements}

This work was funded by Fujian Provincial Health and Family Planning Commission of China (2015-1-72), the Natural Science Foundation of Fujian Province of China (2017J01821), the National Science and Technology Foundation of China for Key Projects of "Major New Drugs Innovation and Development" 


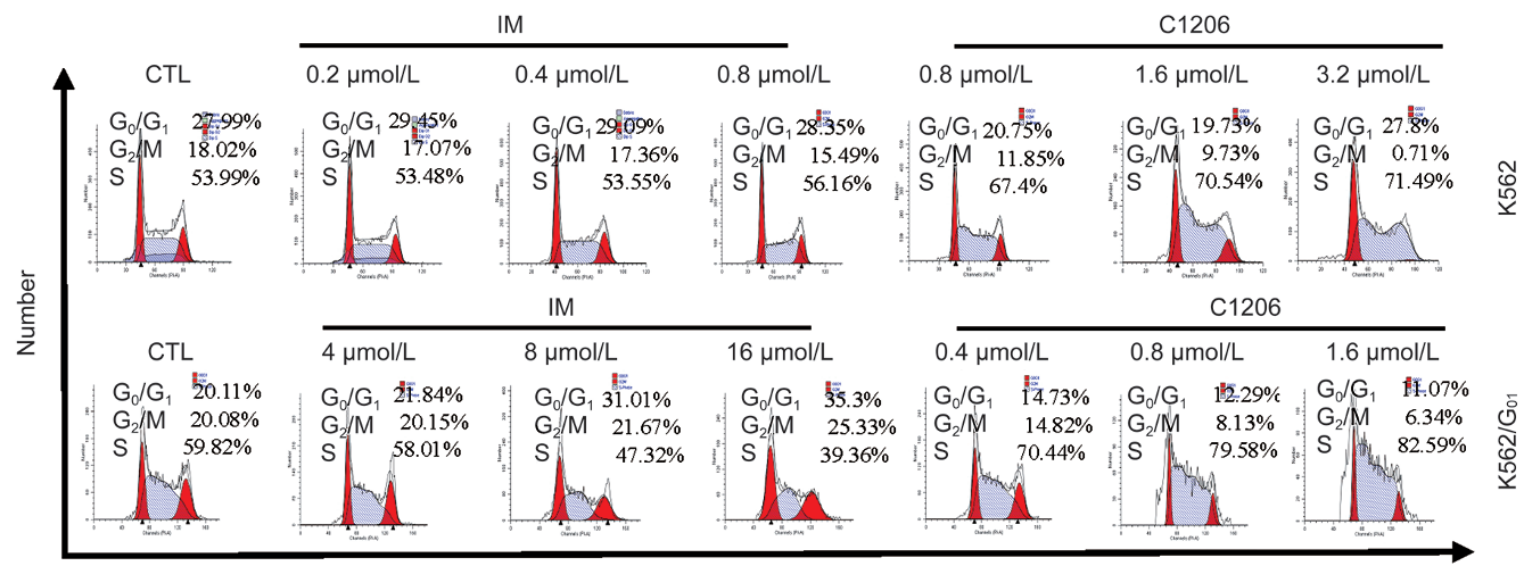

Channels (PI-A)
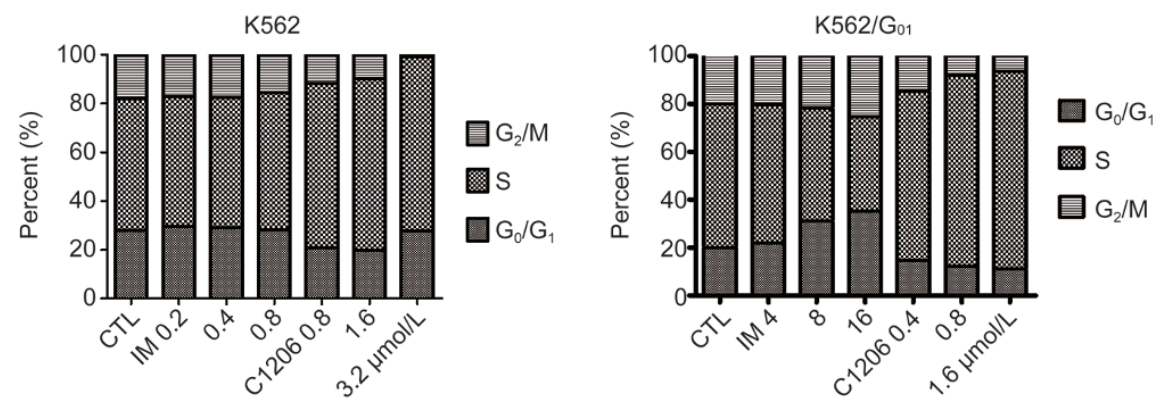

Figure 6. $\mathrm{C} 1206$ induces the $\mathrm{S}$ phase cell cycle arrest in imatinib-sensitive or imatinib-resistant $\mathrm{CML}$ cells. $\mathrm{K} 562$ and $\mathrm{K} 562 / \mathrm{G}_{01}$ cells were treated with $\mathrm{C} 1206$ at the indicated concentrations for $24 \mathrm{~h}$, harvested, and fixed with $70 \%$ ethanol overnight at $-20{ }^{\circ} \mathrm{C}$, harvested, stained with PI and subsequently analysed by flow cytometry.

(2012ZX09103-101-028) and the Joint Funds for the Innovation of Science and Technology, Fujian Province (2016Y9059).

\section{Author contribution}

Jian-hua XU designed research; Ying-juan FAN, Ping-zhang GAO, Fang CAI, Li-ping ZHU and Bi LIU performed research; Lian-ru ZHANG, Yi-xiang ZHOU, Qiao-fa LIN contributed new reagents; Ying-juan FAN, Ping-zhang GAO, Fang CAI, Li-ping ZHU and Bi LIU analyzed data; Ying-juan Fan wrote the paper.

\section{References}

1 Wegele H, Muller L, Buchner J. Hsp70 and Hsp90-a relay team for protein folding. Rev Physiol Biochem Pharmacol 2004; 151: 1-44.

2 Richter K, Hendershot LM, Freeman BC. The cellular world according to Hsp90. Nat Struct Mol Biol 2007; 14: 90-4.

3 Noguchi M, Yu D, Hirayama R, Ninomiya Y, Sekine E, Kubota N, et al. Inhibition of homologous recombination repair in irradiated tumor cells pretreated with Hsp90 inhibitor 17-allylamino-17demethoxygeldanamycin. Biochem Biophys Res Commun 2006; 351: 658-63.

4 Soga S, Neckers LM, Schulte TW, Shiotsu Y, Akasaka K, Narumi H, et al. KF25706, a novel oxime derivative of radicicol, exhibits in vivo antitumor activity via selective depletion of Hsp90 binding signaling molecules. Cancer Res 1999; 59: 2931-8.

5 Harashima K, Akimoto T, Nonaka T, Tsuzuki K, Mitsuhashi N, Nakano T. Heat shock protein 90 (Hsp90)chaperone complex inhibitor, radicicol potentiated radiation-induced cell killing in a hormone-sensitive prostate cancer cell line through degradation of the androgen receptor. Int J Radiat Biol 2005; 81: 63-76.

6 Neckers L. Heat shock protein 90: the cancer chaperone. J Biosci 2007; 32: 517-30.

7 Wu LX, Xu JH, Huang XW, Zhang KZ, Wen CX, Chen YZ. Downregulation of $\mathrm{P} 210^{\mathrm{bcr} / \mathrm{abl}}$ by curcumin involves disrupting the molecular chaperone functions of Hsp90. Acta Pharmacol Sin 2006; 27: 694-9.

8 Chen C, Lui Y, Chen YZ, Xu JH. C086, a novel analog of curcumin, induces growth inhibition and ownregulation of NFKB in colon cancer cells and xenograft tumors. Cancer Biol Ther 2011; 12: 797-807.

9 Wu LX, Yu J, Chen RJ, Liu Y, Lou LG, Wu Y, et al. Dual inhibition of Bcr$\mathrm{Abl}$ and Hsp90 by $\mathrm{C086}$ potently inhibits the proliferation of imatinibresistant CML Cells. Clin Cancer Res 2015; 21: 833-43.

10 Chen JJ, Guo QJ, He XM, Yang SX, Chen C, Zhang LR. Study on a screening model for inhibitor of Hsp90 ATPase activity. J Xiamen Univ 2010; 49: 711-6.

11 Gao PZ, Wu H, Guo J, Xu YM. Study on the interaction between breviscapinum and bovine serum albumin by fluorescence spectrometry. Chin JMAP 2012; 29: 106-9.

12 Meng A, Wang Y, Brown SA, Van ZG, Zhou D. Ionizing radiation and busulfan inhibit murine bone marrow cell hematopoietic function via apoptosis-dependent and -independent mechanisms. Exp Hematol 2003; 31: 1348-56.

13 Zhang G, Keita B, Brochon JC, Oliveira PD, Nadjo L, Craescu CT, et al. Molecular interaction and energy transfer between human serum albumin and polyoxometalates. J Phys Chem B 2007; 111: 1809-14.

14 Chakraborty B, Basu S. Interaction of BSA with proflavin: A spectroscopic approach. J Lumin 2009; 129: 34-9.

15 Pastukhov AV, Levchenko LA, Sadkov AP. Spectroscopic study on 
binding of rutin to human serum albumin. Mol Struct 2006; 842: 60-6.

16 Yan CN, Tong JQ, Xiong D, Liu Y, Pan ZT. Studies on the binding reaction features between pefloxacin and bovine serum albumin by fluorescence spectrophtometry. Chin J Anal Chem 2006; 6: 796800.

17 Ross PD, Subramanian S. Thermodynamics of protein association reactions: forces contributing to stability. Biochemistry 1981; 20: 3096-102.

18 Zhang $X$, Kou ZN, Shi YJ, Zhu JB. Investigation on effect of fluorescence enhancement of Danshensu-BSA system by synchronous fluorescence spectrometry. J Instrument Anal 2011; 30: 444-7.

19 Tretiakova I, Blaesius D, Maxia L, Wesselborg S, Schulze-Osthoff K, Cinatl J Jr, et al. Myrtucommulone from Myrtus communis induces apoptosis in cancer cells via the mitochondrial pathway involving caspase-9. Apoptosis 2008; 13: 119-31.

20 Tian Z, Shen J, Moseman AP, Yang QL, Yang JS, Xiao PG, et al. Dulxanthone A induces cell cycle arrest and apoptosis via upregulation of p53 through mitochondrial pathway in HepG2 cells. Int J Cancer 2008; 122: 31-8.

21 Del BB, Valentini MA, Comporti M, Maellaro E. Cisplatin-induced apoptosis in melanoma cells: role of caspase- 3 and caspase- 7 in Apaf-1 proteolytic cleavage and in execution of the degradative phases. Ann N Y Acad Sci 2003; 1010: 200-4.

22 Troiano L, Ferraresi R, Lugli E, Nemes E, Roat E, Nasi M, et al. Multiparametric analysis of cells with different mitochondrial membrane potential during apoptosis by polychromatic flow cytometry. Nat Protoc 2007; 2: 2719-27.

23 Falsone SF, Gesslbauer B, Tirk F, Piccinini AM, Kungl AJ. A proteomic snapshot of the human heat shock protein 90 interactome. FEBS Lett 2005; 579: 6350-4.

24 Kamal A, Boehm MF, Burrows FJ. Therapeutic and diagnostic implications of Hsp90 activation. Trends Mol Med 2004; 10: 28390.

25 Zhao R, Davey M, Hsu YC, Kaplanek P, Tong A, Parsons AB, et al. Navigating the chaperone network: an integrative map of physical and genetic interactions mediated by the Hsp90 chaperone. Cell 2005; 120: $715-27$

26 Neckers L. Development of small molecule Hsp90 inhibitors: utilizing both forward and reverse chemical genomics for drug identification. Curr Med Chem 2003; 10: 733-9.

27 Whitesell L, Mimnaugh EG, De Costa B, Myers CE, Neckers LM.
Inhibition of heat shock protein Hsp90-pp60v-src heteroprotein complex formation by benzoquinone ansamycins: essential role for stress proteins in oncogenic transformation. Proc Natl Acad Sci U S A 1994; 91: 8324-8.

28 Supko JG, Hickman RL, Grever MR, Malspeis L. Preclinical pharmacologic evaluation of geldanamycin as an antitumor agent. Cancer Chemother Pharmacol 1995; 36: 305-15.

29 Rivera-Espinoza Y, Muriel P. Pharmacological actions of curcumin in liver diseases or damage. Liver Int 2009; 29: 1457-66.

30 Wei JS, Yu ZW, Chiang YC, Yang Y, Chai TY, Folt W, et al. Curcumin prevents high fat diet induced insulin resistance and obesity via attenuating lipogenesis in liver and inflammatory pathway in adipocytes. PLoS One 2012; 7: e28784.

$31 \mathrm{Wu} \mathrm{LX}, \mathrm{Xu} \mathrm{JH}, \mathrm{Wu} \mathrm{GH}$, Chen YZ. Inhibitory effect of curcumin on proliferation of $\mathrm{K} 562$ cells involves down-regulation of $\mathrm{P} 210^{\text {bcr-abl }}$ initiated Ras signal transduction pathway. Acta Pharmacol Sin 2003; 24: 1155-60.

32 Qi J, Peng H, Gu ZL, Liang ZQ, Yang CZ. Establishment of an imatinib resistant cell line $\mathrm{K} 562 / \mathrm{G}_{01}$ and its characterization. Zhonghua Xue Ye Xue Za Zhi 2004; 25: 337-41.

33 Hossain DM, Bhattacharyya S, Das T, Sa G. Curcumin: the multitargeted therapy for cancer regression. Front Biosci (Schol Ed) 2012; 4: 335-55.

34 Pastukhov AV, Levchenko LA, Sadkov AP. Spectroscopic study on binding of rutin to human serum albumin. Mol Struct 2006; 842: 60-6.

35 Felts SJ, Karnitz LM, Toft DO. Functioning of the Hsp90 machine in chaperoning checkpoint kinase I (Chk1) and the progesterone receptor (PR). Cell Stress Chaperones 2007; 12: 353-63.

36 Riggs D, Cox M, Cheung-Flynn J, Prapapanich V, Carrigan P, Smith D. Functional specificity of co-chaperone interactions with Hsp90 client proteins. Crit Rev Biochem Mol Biol 2004; 39: 279-95.

37 Pearl LH, Prodromou C, Workman P. The Hsp90 molecular chaperone: an open and shut case for treatment. Biochem J 2008; 410: 439-53.

38 Whitesell L, Lindquist SL. HSP90 and the chaperoning of cancer. Nat Rev Cancer 2005; 5: 761-72.

39 Sato S, Fujita N, Tsuruo T. Modulation of Akt kinase activity by binding to Hsp90. Proc Natl Acad Sci U S A 2000; 97: 10832-7.

40 Kang BH, Plescia J, Dohi T, Rosa J, Doxsey SJ, Altieri DC. Regulation of tumor cell mitochondrial homeostasis by an organelle-specific Hsp90 chaperone network. Cell 2007; 131: 257-70. 